\title{
DEVELOPMENT OF METRONIDAZOLE MICROSPONGE INCORPORATED INTO CARBOMER-BASED VAGINAL GEL
}

\author{
Sandra Aulia Mardikasari, Arfian Junior Amir, Aliyah, Muhammad Nur Amir, Achmad Himawan, \\ Usmanengsih, Suci Ananda Putri, Irma Nurfadilla Tuany, Andi Dian Permana*
}

Faculty of Pharmacy, Hasanuddin University, Makassar, Indonesia

Received - December 28, 2020; Revision - March 23, 2021; Accepted - April 29, 2021

Available Online - September 08, 2021

DOI: http://dx.doi.org/10.18006/2021.9(Spl-2-ICOPMES_2020).S241.S247

\section{KEYWORDS \\ Bacterial Vaginosis (BV) \\ Metronidazole \\ Microsponge \\ Gel \\ Vaginal delivery system}

\begin{abstract}
Bacterial vaginosis (BV) is a vaginal infection caused by excessive bacterial growth, thus disrupting the natural balance of bacteria inside the vagina. Metronidazole becomes a drug of choice and a widely prescribed drug for the treatment of BV. However, when applied topically, metronidazole has a low vaginal residence time because of the natural washing mechanism of the vagina. This study aimed to improve the retention time of metronidazole inside the vagina and control its release profile. This study was prepared 4 formulas of gel for metronidazole microsponges with some concentration ratio of carbomer and triethanolamine. The evaluations carried out to test the efficacy of the developed formulation included organoleptic, $\mathrm{pH}$ measurement, spreadability, viscosity, mucoadhesive properties, permeation test using Franz diffusion cell and retention test. The results showed that the gel appearance was white, odourless and homogenous. The characteristics of all prepared gel for $\mathrm{pH}$, viscosity, spreadability, and mucoadhesive ability were appropriate to the required standard for vaginal delivery. The permeation and retention test showed that F3 with the carbomer and triethanolamine concentration of $1.25 \%: 1.75 \%$ was able to retain and controlled the drug release locally in the vaginal mucosa. This study provides an alternative strategy in drug formulation for the treatment of $\mathrm{BV}$.
\end{abstract}

* Corresponding author

E-mail: andi.dian.permana@ farmasi.unhas.ac.id (Andi Dian Permana)

Peer review under responsibility of Journal of Experimental Biology and Agricultural Sciences.

Production and Hosting by Horizon Publisher India [HPI] (http://www.horizonpublisherindia.in/).

All rights reserved.
All the articles published by Journal of Experimental Biology and Agricultural Sciences are licensed under a Creative Commons Attribution-NonCommercial 4.0 International License Based on a work at www.jebas.org.

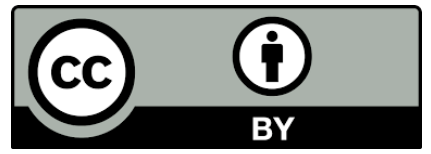




\section{Introduction}

Bacterial vaginosis (BV) is a common vaginal infection that disrupts the natural balance of bacteria in the vagina (Larsson \& Carlsson, 2002). BV is characterized by an overgrowth of vaginal anaerobic bacteria and depletion of the normal Lactobacillus population (Kumar et al., 2011). BV can cause several complications, which include fishy vaginal discharge, malodours, stomach pain, high HIV risk, preterm birth and urinary tract infection (Kumar et al., 2011). For the treatment of BV, a lot of antimicrobial agents have been used. Metronidazole is the widely prescribed drug for the treatment of $\mathrm{BV}$.

Metronidazole has been reported to be effective in oral and topical applications (locally) for the treatment of BV(van de Wijgert et al., 2020). However, the oral preparation of metronidazole shows some side effects in the gastrointestinal tract (Hernández et al., 2019). Therefore, locally administered metronidazoles are generally preferable. The intravaginal delivery of metronidazole showed a better result but because of the low vaginal residence time due to the natural-washing mechanism of the vagina, it took a longer period of treatment (Kumar et al., 2011). The mucoadhesive vaginal gel can be used to keep the drug in the vagina for a certain period but it is releasing the drug slowly. Besides that, it is important to prolong the retention time of the drug inside the vagina to gain optimal drug absorption by controlling the drug release. The use of microsponge in the mucoadhesive vaginal gel can be an alternative strategy in drug administration for the treatment of vaginal infections (Sangeetha \& Karki, 2015; Kalita et al., 2017). Microsponges is a controlled drug release system consists of small porous microspheres which then slowly release the encapsulated materials (active substances)(Mahant et al., 2020). The microsponge can be formulated as a mucoadhesive gel by using a suitable gelling agent for ease of use (Nagula \& Wairkar, 2020). Controlling the release of drugs locally will improve the efficacy of formula with a decrease in dosing frequency and fewer side effects. The mucoadhesive gel can attach drugs to the target area so that it can overcome the problem of drugs that could easily be eliminated by the vagina (Andrade et al., 2014).

Carbomer is the most commonly used gelling agent in the manufacture of gels and is particularly meant for the application on mucous membranes. Carbomer has a high molecular weight, containing some carboxyl groups, allowing them to dissolve easily in the body fluids. The hydrogen bonding between the carbomer and mucosal fluids can facilitate the adhesion properties in the mucosa vaginal (Andrade et al., 2014). Several previous studies have used carbomers as polymers in microsponge gel formulations and the results showed that carbomers can stick to the mucosa and the swelling process occurs in the water while releasing the drug into the vagina (Shaikh et al., 2011; Salah et al., 2018). The use of carbomers in mucoadhesive vaginal gel preparations has shown a good distribution. In addition, the use of carbomers is safe, available in large quantities, effective over a wide $\mathrm{pH}$ range, and can maintain physico-chemical properties at extreme temperatures.

This study aimed to develop a mucoadhesive vaginal gel containing metronidazole's microsponges with various carbomer concentrations as a gelling agent. This formulation can improve the retention time of metronidazole inside the vaginal and control the profile. In this study, metronidazole's microsponge was incorporated into the carbomer-based vaginal gel. Then the prepared formulations were characterized for $\mathrm{pH}$, spreadability, viscosity, mucoadhesive properties, permeation ability and retention profile.

\section{Materials and Methods}

\subsection{Material}

Aquadest, Carbomer (Merck, UK), Ethyl Celulose (Sigma, UK), Dichloromethane (Merck, UK), DMDM Hydantoin (Merck, UK), Metronidazole (Sigma, UK), Microsponge Metronidazole, Polivinilalkohol (PVA) (Sigma, UK), Glycerin, Triethanolamine (Merck, UK), NaCl (Merck, UK), KOH (Merck, UK), albumin serum (Merck, UK), lactic acid (Merck, UK), acetic acid (Merck, UK), urea (Merck, UK), and glucose (Merck, UK). All other chemicals and solvents used are of analytical grade.

\subsection{Preparation of mucoadhesive gel}

The mucoadhesive gel is prepared by using the formula given in table 1 with a slight modification (Kalita et al., 2017). Briefly, carbopol gel was prepared by dispersing in a sufficient quantity of water according to the concentration in each formula and allowed to hydrate overnight. Then, adjusting its $\mathrm{pH}$ by dropwise adding the aqueous solution of triethanolamine until a clear gel was formed. Finally, DMDM Hydantoin, glycerin and metronidazolemicrosponge were added with continuous stirring until homogeneous (Sangeetha \& Karki, 2015).

Table 1 Formulation of Mucoadhesive Gel

\begin{tabular}{|cc|ccc|}
\hline Composition $(\% \mathrm{~b} / \mathrm{b})$ & $\mathrm{F} 1$ & $\mathrm{~F} 2$ & $\mathrm{~F} 3$ & $\mathrm{~F} 4$ \\
\hline $\begin{array}{c}\text { Microsponge } \\
\text { (Metronidazole } 0.75 \%)\end{array}$ & 1 & 1 & 1 & 1 \\
\hline Triethanolamine & 1 & 1.5 & 1.75 & 2 \\
\hline DMDM Hydantoin & 0.1 & 0.1 & 0.1 & 0.1 \\
\hline Glycerine & 15 & 15 & 15 & 15 \\
\hline Carbomer & 0.75 & 1 & 1.25 & 1.5 \\
\hline Aquadest & 82.15 & 81.4 & 80.9 & 80.4 \\
\hline
\end{tabular}




\subsection{Determination of the $\mathrm{pH}$}

$\mathrm{pH}$ of Metronidazole microspongegel's was measured by using a $\mathrm{pH}$-meter by inserting the electrode tip into the gel and after 2 minutes the results were recorded (Dineshmohan \& Gupta, 2017).

\subsection{Determination of the viscosity}

The viscosity of Metronidazole microsponge gel was evaluated using a Brookfield Viscometer with 7-spindle operating at $50 \mathrm{rpm}$ (Manna et al., 2016; Dineshmohan \& Gupta, 2017).

\subsection{Determination of spreadability}

Spreadability was accessed by placing 1 gram of gel on a glass plate then covered with another glass plate, and then a pressure of 125-525 $\mathrm{g}$ was applied for 5 minutes. The diameter of the spreading circle is measured using a calliper (Dineshmohan \& Gupta, 2017).

\subsection{Determination of the mucoadhesive properties}

These mucoadhesive properties of the prepared formulation were evaluated by using the rotating cylinder method with a slightly modified dissolution apparatus (Shaikh et al., 2011). The temperature is maintained at $37^{\circ} \mathrm{C}$, rotation speed was about 100 rpm. The bovine vaginal mucosa is clamped and attached to the paddle side. After that, the gel formulation was applied approximately $500 \mathrm{mg}$ to the entire bovine vaginal mucosa and immersed in an artificial vaginal fluid $(\mathrm{pH} 4.2)$. The retention time was determined by the length of time the gel formulation takes to be released from the bovine vaginal mucosa.

\subsection{Permeation study}

In vitro drug release study was investigated using the modified Franz diffusion cell with the bovine vaginal mucosa. The prepared bovine vaginal mucosa was placed between the donor and receptor compartment. The receptor compartment was filled with a capacity of $28 \mathrm{ml}$ of artificial vaginal fluid at $\mathrm{pH} 4.2$ operating at $100 \mathrm{rpm}$ on a magnetic stirrer. The temperature was maintained at $37 \pm 1^{\circ} \mathrm{C}$. About 1 $\mathrm{mL}$ sample of each formula was spread on the donor compartment. At defined time intervals of 15, 30, 45, 60, 120, 180, 240, 300, 360, 420, and $480 \mathrm{~min} 1.5 \mathrm{~mL}$ of sample was withdrawn and replaced with an equal volume of receptor medium. Aliquots were diluted and analyzed using UV-spectrophotometer at $320 \mathrm{~nm}$ (Machado et al., 2015). In this study, a control is needed to evaluate and compare the permeation ability of the mucoadhesive gel formulations. A gel containing pure metronidazole was used as a control.

\subsection{Vaginal retention study}

Vaginal retention study was performed to determine the content of the drug on the skin. After the in vitro drug release study, the bovine vaginal mucosa was washed with $30 \mathrm{~mL}$ artificial vaginal fluid ( $\mathrm{pH}$ 4.2) using a homogenizer at $1000 \mathrm{rpm}$ for 15 minutes.
Then centrifugation for 30 minutes at a speed of $5000 \mathrm{rpm}$ and analyzed using UV-spectrophotometer at $320 \mathrm{~nm}$.

\subsection{Preparation of simulated vaginal fluid}

A total of 5 grams of glucose, 3.51 grams of $\mathrm{NaCl}, 2$ grams of lactic acid, 1.4 grams of $\mathrm{KOH}, 1$ gram of acetic acid, 0.4 grams of urea, 0.222 grams of $\mathrm{Ca}(\mathrm{OH})_{2}, 0.018$ grams of serum albumin, and 0.016 grams of glycerin, weighed then dissolved in $1 \mathrm{~L}$ of deionized water and adjust $\mathrm{pH} 4.2$ by the addition of $0.1 \mathrm{~N} \mathrm{HCl}$ (Sanz et al., 2018)

\subsection{Statistical analysis}

All data were collected and analyzed using a statistical approach with the One Way ANOVA method (Andrade et al., 2014).

\section{Results and Discussion}

\subsection{Preparation of mucoadhesive gel}

In this study, a microsponge mucoadhesive gel was formulated to control the release of metronidazole locally and increase the residence time of the preparation in the vaginal mucosa. Carbomer was used as a gelling agent and mucoadhesive material. The concentration of carbomer was a range between $0.5 \%-2 \%$. Carbomer requires a neutralizing agent to form a transparent gel. The addition of triethanolamine (TEA) could neutralize the carbomer. An excessive neutralization (optimal pH 5-10) can reduce the viscosity of the formed gel (Rowe et al., 2009). The concentration of TEA that neutralizes carbomer is 1.5: 1 . In this research, all formulas were developed with various concentrations of TEA and Carbomer to gain suitable properties of the mucoadhesive gel. The gel formula was made using a homogenizer with a concentration ratio of carbomer and triethanolamine. The ratio for each formula was F1 (0.75: 1) ; F2 (1: 1.5) ; F3 (1.25 : 1.75) ; and F4 (1.5:2). Physical appearances of all gel formulations were visually inspected figure 1 showed that all formulated gels were white in colour and odourless.

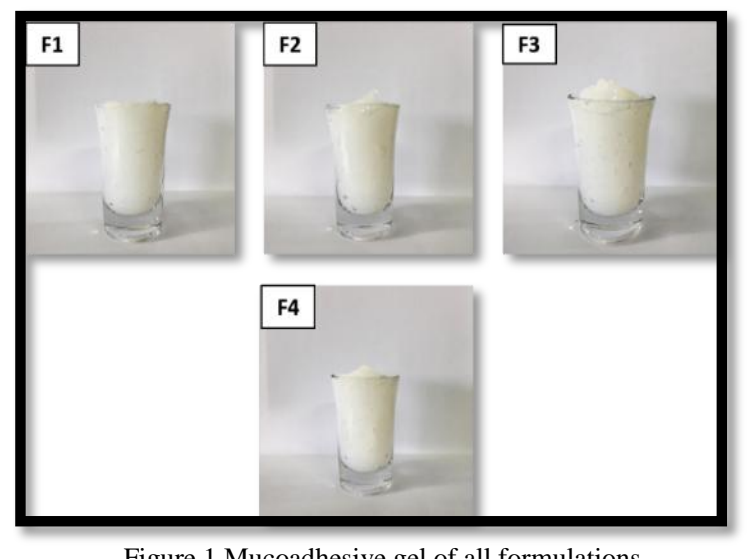

Figure 1 Mucoadhesive gel of all formulations (a) F1, (b) F2, (c) F3, (d) F4 


\subsection{Determination of the $\mathrm{pH}$}

The $\mathrm{pH}$ of all developed formulations was measured by using a $\mathrm{pH}$ meter. The normal vaginal $\mathrm{pH}$ was ranged between 3.5-4.5, however, the vaginal $\mathrm{pH}$ will increase with the occurrence of bacterial vaginosis. The vaginal $\mathrm{pH}$ with $\mathrm{VB}$ reached 6.5-8 (Borges et al., 2016). Figure 2 showed that the $\mathrm{pH}$ of the various formulation of microsponge gel viz., F1, F2, F3, F4 was $6.87 \pm$ $0.02 ; 6.99 \pm 0.02 ; 7.03 \pm 0.02 ; 7.09 \pm 0.02$, respectively. According to the statistical analysis results, the ratio of the concentrations between carbomer and triethanolamine for F2 and F3 did not significantly affect the $\mathrm{pH}(\mathrm{p}<0.05)$. It can be concluded that the $\mathrm{pH}$ of all formulas was still within the range of vaginal $\mathrm{pH}$ affected by $\mathrm{BV}$. Assessment of $\mathrm{pH}$ has a very important role because if the $\mathrm{pH}$ is too acidic $(<4)$, it causes the growth of Lactobacillus vaginalis bacteria and vaginal discharge, whereas a $\mathrm{pH}$ that is too alkaline (>8), it can causes the growth of cocci bacteria that causes Vaginosis. So that it becomes very important to keep the $\mathrm{pH}$ following VB conditions.

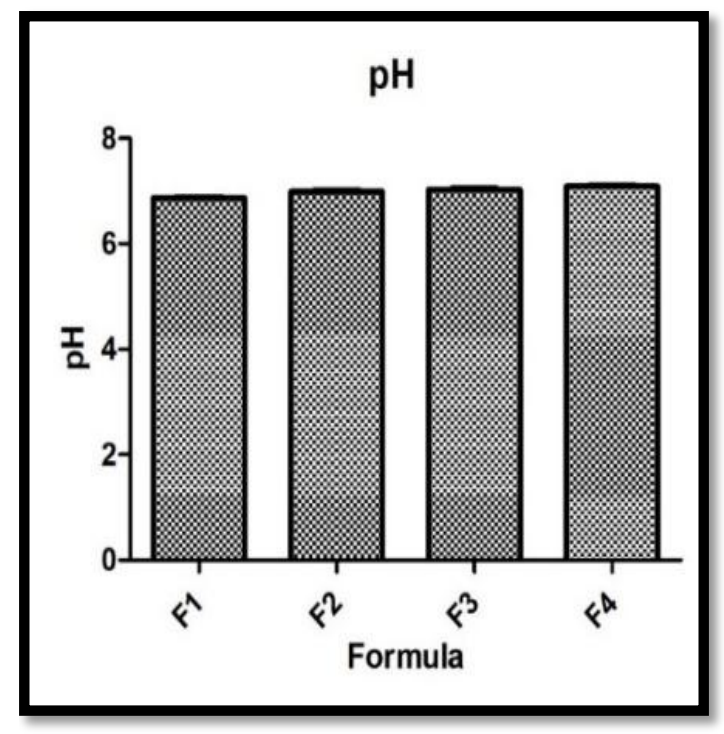

Figure $2 \mathrm{pH}$ of all gel formulations

\subsection{Determination of spreadability}

The spreadability test is one of the important characteristics of topical formulations. Measurement of the spreadability was carried out using callipers to determine the ability of the preparation to spread when applied to the vagina. The gel formula for the vagina should have good spreadability and ease of application. Figure 3 showed the spreadability of microsponge gel range between 3.22 $3.98 \mathrm{~cm} / \mathrm{s}$. There was a slight decrease in spreading diameters. This variation might be due to variation in polymer concentration in each gel formula.
Viscosity affects the width of the spreading area, where the smaller the viscosity value, the smaller the resistance of the gel preparation to spread, resulting in a large spreadability value. Conversely, if the viscosity value is greater, the resistance of the gel preparation to spread is also greater, thus reducing the spreadability value make the gel thicker. Based on the previous study of Garg et al. (2002), the diameter of semi-solid preparations that are suitable for topical use is in the $3-5 \mathrm{~cm}$ range or it can be stated that the area of spreadability is between $7.605-19.625 \mathrm{~cm}^{2}$. Based on statistical results, all the preparations were significantly different ( $p<0.05)$. According to the research of Kalita et al. (2017), the spreadability of microspheres gel of metronidazole preparations was ranging from 3.5-5.5 g.cm/sec. From the data presented in table 1, it can be concluded that the spreadability value for F3 and F4 were in the appropriate range.

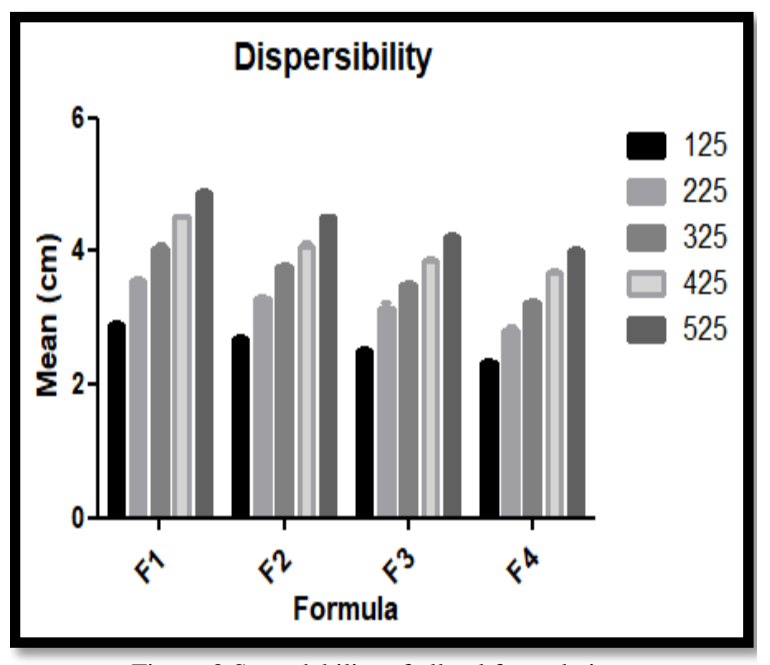

Figure 3 Spreadability of all gel formulations

\subsection{Determination of viscosity}

Viscosity measurement was carried out by immersing the spindle into the gel preparation. The viscosity value of microsponge gel for F1, F2, F3 and F4 was reported $25800 \pm 1053.57 \mathrm{cPs}$; $32766.67 \pm 650.64 \mathrm{cPs} ; 38133.33 \pm 1514.38 \mathrm{cPs}$; and $47666.67 \pm$ $2722.74 \mathrm{cPs}$, respectively (Figure 4).

The data shows that there is a significant increase in viscosity of all four formulas ( $p$ <0.05). Based on the literature, the viscosity value for gels preparation using carbomeric polymers must be in the range of 10000-60000 cPs (Rowe et al., 2009). By increasing the concentration of the polymer used, the viscosity of the preparation will also increase. According to Dineshmohan \& Gupta (2017), the viscosity value of microsponge gel obtained was in the range of 34,480-91,350 cPs. Therefore, the viscosity values of F3 and F4 were in the appropriate ranges. 


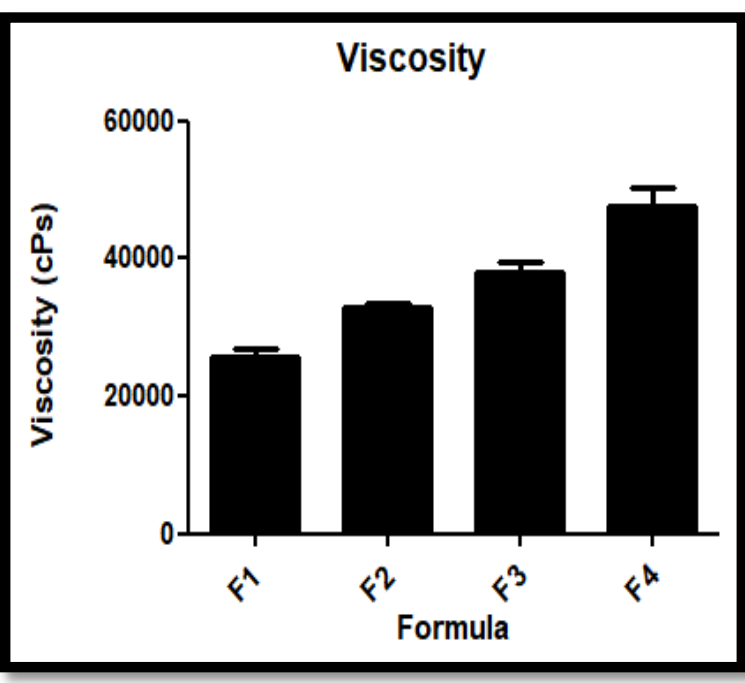

Figure 4 Viscosity of all gel formulations

\subsection{Determination of mucoadhesive properties}

Measurement of the strength of the mucoadhesive gel was carried out using the Rotating Cylinder Method. The microsponge gel had a mucoadhesive time of F1 $2.5 \pm 0.1$ hours, F2 $4.3 \pm 0.2$ hours, F3 6.4 \pm 0.2 hours, and F4 $6.4 \pm 0.1$ hours. Gel preparations for the vagina must have good bioadhesive strength because the strength of the bioadhesive affects the contact time of the preparation with the mucosa in the vagina. The high bioadhesive strength will increase the contact time of the preparation in the vagina, the use of carbomeric polymers can increase the contact time of the preparation with the mucosa, from 1-2 hours to 3-4 days, prolonged contact with mucosa accompanied by slow release of the drug at the target location. Based on the statistical results, it shows that there is a significant effect ( $p>0.05$ ) between the concentration of the carbomer polymer on the viscosity so that it can affect the bioadhesive strength of the preparation. According to Sanz et al.

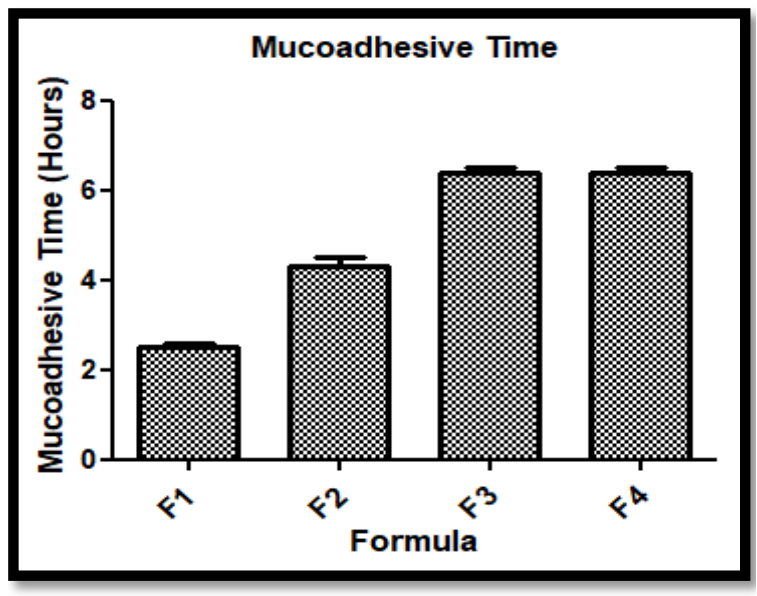

Figure 5 Mucoadhesive time of all gel formulations
(2018), 6 hours of the trial is considered sufficient to assess the drug can be released on the mucosa. Thus, the F3 and F4 preparations have the highest bioadhesive strength and it can be said that this formula is suitable for bioadhesive gel preparations. A preparation that can provide a long contact time at the site of administration is needed so that drug release can be controlled locally (Shaikh et al., 2011).

\subsection{Permeation study}

The determination of the metronidazole content was carried out using spectrophotometric analysis. In spectrophotometric analysis, it was found that the wavelength of metronidazole was $320 \mathrm{~nm}$. The amount of permeated metronidazole was shown in figure 6. For F1, F2, F3, and F4 the value was reported $0.51 \pm$ $0.02 \mathrm{mg} ; 0.42 \pm 0.01 \mathrm{mg} ; 0.28 \pm 0.01 \mathrm{mg} ;$ and $0.16 \pm 0.02 \mathrm{mg}(\mathrm{p}$ $<0.05$ ), respectively. The amount of drug permeated for F1 to F4 tends to decrease due to the viscosity value and the properties of the mucoadhesive gel. The greater viscosity represented the smaller the amount of drug released from the gel preparation (Shaikh et al., 2011). A gel containing pure metronidazole was used as a control in this study. From the obtained data, the number of permeated from the control formula was greater than the number of permeated from the four formulas, namely $1.14 \pm$ $0.02 \mathrm{mg}$. This is because metronidazole in the control formula does not have a retention time so that it can be released immediately. One of the aims of the microsponge gel formulation is to release the drug in a controlled release for local delivery, if the amount of permeated is high, the drug can directly penetrate or pass through the membrane (Patel et al., 2016). From the given figure 6 , it was observed that microsponge gels of F1, F2, F3, and F4 show a small permeation value compared to the control, therefore the level of metronidazole released can be controlled and the desired local effect can be achieved.

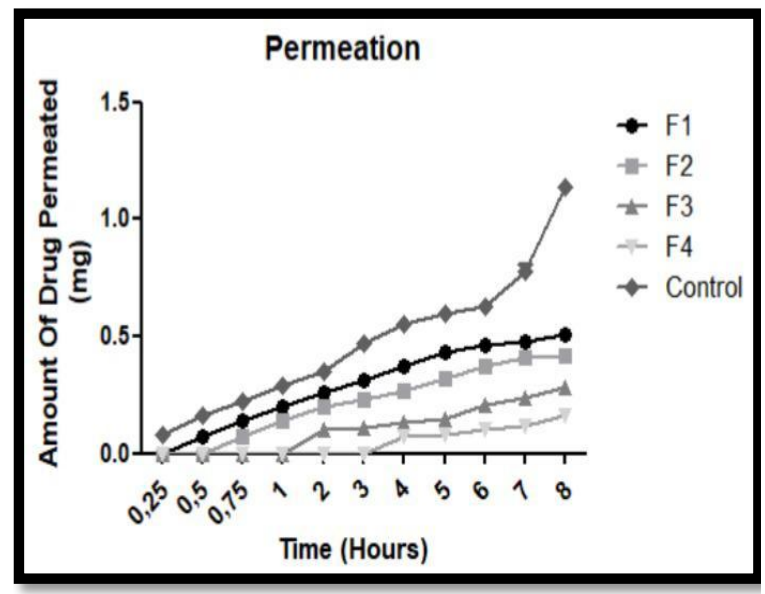

Figure 6 Permeation Study

Journal of Experimental Biology and Agricultural Sciences http://www.jebas.org 


\subsection{Vaginal retention study}

The permeation data does not fully support the desired local effect because the permeation test is carried out to determine the amount of drug that can pass through or penetrate the membrane. Meanwhile, to ensure that the preparation can work locally, the amount of metronidazole that can be left on the membrane must be known, therefore it is necessary to carry out a retention test for the preparation. In addition, the retention test aimed to determine the ability to control drug release from the dosage form.

Figure 7 shows the percentage of metronidazole deposited after 8 hours. One of the importance of the microsponge gel system is that it can be used to increase the residence time of the drug in the vagina. Based on the figure 7 , the amount of metronidazole that was deposited after 8 hours was mostly at F3 $(1.95 \pm 0.04 \mathrm{mg})$, compared to the amount of metronidazole at F1 $(0.51 \pm 0.02 \mathrm{mg})$; F2 $(0.73 \pm 0.03 \mathrm{mg})$ and F4 $(0.08 \pm 0.01 \mathrm{mg})$, the obtained data was significantly different $(\mathrm{p}<0.05)$. This shows that F3 has the best retention time, so it can control the release of metronidazole locally in the vagina. For microsponge gel preparation at F4, the amount of deposited metronidazole was low, however, it also had a low amount of permeated metronidazole and was significantly different $(\mathrm{p}<0.05)$. This suggests that the higher carbomer concentration can control the permeates well but does not have a high retention time in the vagina, so it tends to release the drug and reach to the systemic circulation without providing the desired local effect. This is might be due to an excessive concentration of carbomer used in the F4 which resulting in a very viscous gel preparation. In the above histogram, the control formula which consists of pure metronidazole, shows that the amount of metronidazole deposited is less than the metronidazole microsponge gel formula, so it is known that the control formula has a greater amount to release immediately to reach the systemic

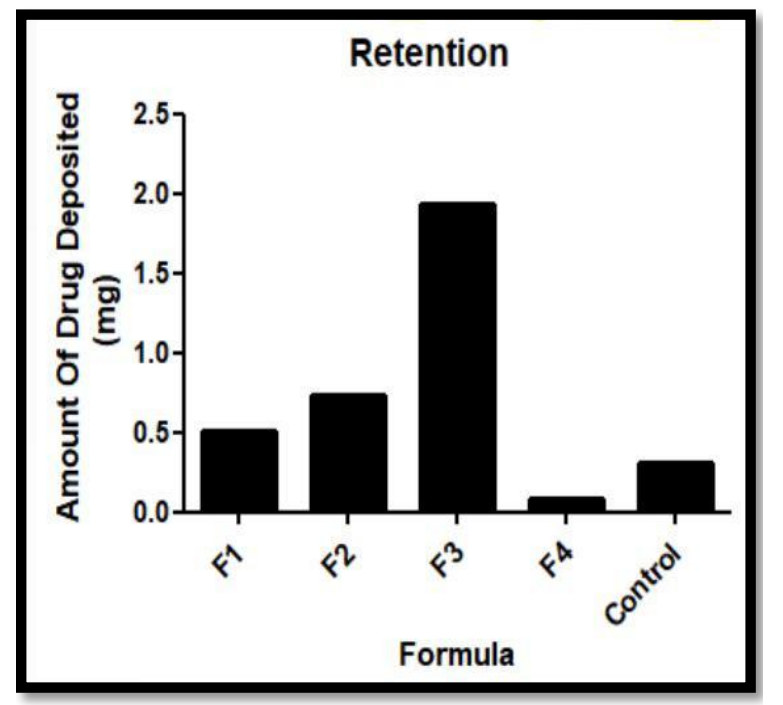

Figure 7 Retention profile of all gel formulations and control circulation compared to the amount left in the membrane vagina. This is consistent with previous research (Patel et al., 2016) which states that when the release of metronidazole is not controlled, it can directly reach the systemic circulation.

\section{Conclusion}

The prepared gel of all formulas was white, odourless, and homogenous. The ratio of carbomer concentration showed a significant effect on $\mathrm{pH}$ and permeation study but not significant on the dispersion, viscosity, mucoadhesive time and retention study. Furthermore, the results showed that F3 is the best formula which has a low amount of permeation and a high amount of retention.

\section{Conflict of Interest}

The authors declare no conflict of interest.

\section{References}

Andrade AO, Parente ME, Ares G (2014) Screening of mucoadhesive vaginal gel formulations. Brazilian Journal of Pharmaceutical Sciences 50(4): 931-942. https://doi.org/10.1590/ S1984-82502014000400029.

Borges S, Barbosa J, Teixeira P (2016) Drug Delivery Systems for Vaginal Infections. Frontiers in Clinical Drug Research Anti Infectives 2:233-258. https://doi.org/10.2174/9781681081533116020009.

Dineshmohan S, Gupta VRM (2017) Formulation of fluconazole as topical antifungal gels by microsponge based delivery systems. Indonesian Journal of Pharmacy 28(3): 158167.https://doi.org/10.14499/indonesianjpharm28iss3pp157.

Garg A, Aggarwal D, Garg S, Singla AK (2002) Spreading of semisolid formulations: An update.Pharmaceutical Technology North America 26(9): 84-105.

Hernández CA, Romero-Quezada J, Ruvalcaba L (2019) Therapeutic uses of metronidazole and its side effects: An update. European Review for Medical and Pharmacological Sciences 23(1): 397-401. https://doi.org/10.26355/eurrev_201901_16788.

Kalita B, Saikia K, Kalita B (2017) Formulation and evaluation of metronidazole microspheres-loaded bioadhesive vaginal gel. Asian Journal of Pharmaceutical and Clinical Research 10(3): 418-424. https://doi.org/10.22159/ajpcr.2017.v10i3.16417.

Kumar N, Behera B, Sagiri SS, Pal K, Ray SS, Roy S (2011) Bacterial vaginosis: Etiology and modalities of treatment - A brief note. Journal of Pharmacy and Bioallied Sciences 3(4): 496-503. https://doi.org/10.4103/0975-7406.90102.

Journal of Experimental Biology and Agricultural Sciences http://www.jebas.org 
Larsson PG, Carlsson B (2002) Does pre- and postoperative metronidazole treatment lower vaginal cuff infection rate after abdominal hysterectomy among women with bacterial vaginosis? Infectious Disease in Obstetrics and Gynecology 10(3): 133140.https://doi.org/10.1155/S1064744902000133.

Machado RM, Palmeira-de-Oliveira A, Gaspar C, Martinez-deOliveira J, Palmeira-de-Oliveira R (2015) Studies and methodologies on vaginal drug permeation. Advanced Drug Delivery Reviews 92 14-26.https://doi.org/10.1016/j.addr.2015.02.003.

Mahant S, Kumar S, Nanda S, Rao R (2020) Microsponges for dermatological applications: Perspectives and challenges. Asian Journal of Pharmaceutical Sciences 15(3): 273-291. https://doi.org/10.1016/j.ajps.2019.05.004.

Manna S, Lakshmi US, Racharla M, Sinha P, Kanthal LK, Kumar SPN (2016) Bioadhesive HPMC gel containing gelatin nanoparticles for intravaginal delivery of tenofovir. Journal of Applied Pharmaceutical Science 6(08): 022-029. https://doi.org/10.7324/JAPS.2016.60804.

Nagula RL, Wairkar S (2020) Cellulose microsponges based gel of naringenin for atopic dermatitis: Design, optimization, in vitro and in vivo investigation. International Journal of Biological Macromolecules 164: 717-725.https://doi.org/10.1016/ j.ijbiomac.2020.07.168.

Patel N, Padia N, Vadgama N, Raval M, Sheth N (2016) Formulation and evaluation of microsponge gel for topical delivery of fluconazole for fungal therapy. Journal of Pharmaceutical Investigation 46(3):221238.https://doi.org/10.1007/s40005-016-0230-7.
Rowe RC, Sheskey PJ, Quinn ME (2009) Handbook of Pharmaceutical Excipients (6th Edition). Pharmaceutical Press.

Salah S, Awad GEA, Makhlouf AIA (2018) Improved vaginal retention and enhanced antifungal activity of miconazole microsponges gel: Formulation development and in vivo therapeutic efficacy in rats. European Journal of Pharmaceutical Sciences 114 : 255-266. https://doi.org/10.1016/j.ejps.2017.12.023.

Sangeetha SS, Karki R (2015) Formulation and evaluation of liposomes in carbopol gels for mixed vaginal infections. Der Pharmacia Lettre 7(5): 291-299.

Sanz R, Mallandrich M, Suñer-Carbó J, Montes MJ, Calpena AC (2018) Development of a mucoadhesive delivery system for control release of doxepin with application in vaginal pain relief associated with gynecological surgery. International Journal of Pharmaceutics 535(1-2): 393-401. https://doi.org/10.1016/ j.ijpharm.2017.11.027.

Shaikh R, Raj Singh T, Garland M, Woolfson A, Donnelly R (2011) Mucoadhesive drug delivery systems. Journal of Pharmacy and Bioallied Sciences 3(1): 89-100. https://doi.org/10.4103/09757406.76478 .

Van de Wijgert JHHM, Verwijs MC, Agaba SK, Bronowski C, Mwambarangwe L, Uwineza M, Lievens E, Nivoliez A, Ravel J, Darby AC (2020) Intermittent Lactobacilli-containing Vaginal Probiotic or Metronidazole Use to Prevent Bacterial Vaginosis Recurrence: A Pilot Study Incorporating Microscopy and Sequencing. Scientific Reports 10(1): 1-15. https://doi.org/ 10.1038/s41598-020-60671-6. 